\title{
İmplant dayanak bağlantı tiplerinin implant başarısına etkisinin retrospektif olarak değerlendirilmesi: Pilot çalışma*
}

\author{
Fatma Uslu(0000-0003-0414-0652) ${ }^{\alpha}$, Burcu Evlice(0000-0003-3384-0092) $)^{\beta}$, M.Emre Benlidayı(0000-0002-6102-9136) ${ }^{\nu}$, \\ Yurdanur Uçar(0000-0003-0505-8685) ${ }^{\alpha}$
}

Selcuk Dent J, 2020; 7: 1-7 (Doi: 10.15311/selcukdentj.492513)

Başvuru Tarihi: 05 Aralık 2018 Yayına Kabul Tarihi: 17 Ocak 2019

Öz

İmplant dayanak bağlantı tiplerinin implant başarısına etkisinin retrospektif olarak değerlendirilmesi: Pilot çalışma

Amaç: Bu çalışmanın amacı farklı implant dayanak bağlantı tiplerinin (konik ve uç uca birleşim) implant başarısına etkisini değerlendirmektir.

Gereç ve Yöntemler: Kliniğimizde 2016 yilında implant üstü sabit protetik tedavisi tamamlanmış ve yükleme sonrası en az 1 yıllık kontrolleri yapılmış hastalar, dental implant tedavisi için risk oluşturabilecek parametreleri (yaş, medikal durum, meslek, cinsiyet, sigara kullanımı) değerlendirebilmek için çalışmaya dahil edildi. Klinik (sondlamada kanama, cep derinliği, plak indeksi, gingival indeks) ve radyografik (kemik kaybı miktarı) değerlendirmeler kaydedildi. Konik ve uç uca (butt-joint) birleşimi olan implantların başarısı karşılaştırıldı. Farklı implant sistemleri de implant başarısı açısından karşılaştırıldı. Veri analizinde t-testi, tek yönlü ANOVA ve Tukey testleri kullanıldı $(\alpha=0.05)$.

Bulgular: Kliniğimizde kullanılan farklı dental implantlar (Implantium, Nucleoss, Bego, Astra EV, Biohorizons) ile tedavi edilen 19 hastada uygulanan 11 konik ve 8 uç uca birleşimli implant dayanak bağlantısının implant başarısına etkisi yüklemeden bir yıl sonra değerlendirildi. Sondlamada kanama, cep derinliği, plak indeksi, gingival indeks ve kemik kaybı miktarı açısından değerlendirildiğinde iki implant dayanak bağlantı tipi arasında istatiksel olarak anlamlı bir fark bulunamadı $(p>0.05)$. İmplant sistemleri kendi aralarında ayrı ayrı değerlendirildiğinde kısa dönem implant başarısı açısından istatistiksel olarak anlamlı bir fark görülmedi $(p>0.05)$.

Sonuç: Bu retrospektif pilot çalışma çalışmanın sınırlamaları dahilinde implant dayanak bağlantısının kısa dönem implant başarısı üzerinde fark yaratmadığını gösterdi. İmplant dayanak bağlantı tipinin implantın uzun dönem başarısı üzerine etkisini daha büyük örneklem kullanılarak uzun dönem değerlendiren klinik araştırmalara intiyaç duyulmaktadır.

\section{ANAHTAR KELIMELER}

Alveoler kemik kaybı, diş implantı

Dental implantolojinin amacı, peri-implant dokularını uzun vadede korumaktır., ${ }^{1,2}$ Dental implant yerleşimi sonrası kemik remodelasyon sürecinin kemik kaybını etkileyeceği bilinmektedir. ${ }^{3,4}$ Implant destekli sabit

\section{ABSTRACT}

A retrospective study on effect of implant-abutment connection on implant success: A pilot study

Background: The aim of this study was to analyze the effect of implant abutment connection on implant success.

Methods: Patients who were rehabilitated in our clinic with implant supported fixed dental prosthesis in 2016 and followed up at least one year after loading were involved in the study. Risk parameters that might affect dental implant success were evaluated. Clinical (bleeding on probing, pocket probing depth, plaque index, gingival index) and radiographic evaluations (marginal bone loss) were recorded. Success of dental implants with conic and butt-joint connections were compared. Different dental implant brands were also evaluated. Data analysis was done using t-test, one-way ANOVA and Tukey tests $(\alpha=0.05)$.

Results: Nineteen patients were rehabilitated with dental implants (Implantium, Nucleoss, Bego, Astra EV, Biohorizons). Eleven conic, eight butt-joint implant-abutment connections were evaluated after one year of loading. Implant abutment connection did not have a statistically significant effect on bleeding on probing, pocket depth, plaque index, gingival index and bone loss $(p>0.05)$. No statistically significant difference was found on short-term implant success when different implant brands were compared $(p>0.05)$. Further clinical studies are required to evaluate the effects of implant abutment connection type on the long-term success of implants.

Conclusion: Within the limitations of this retrospective clinical study, results reveal that the design of the implant-abutment connection appears to have no significant impact on short-term implant success. Further clinical studies with much larger sample size are required to evaluate the effects of implant abutment connection type on the long-term success of implants.

\section{KEYWORDS}

Alveolar bone loss, dental implant

restorasyonlarda yüksek başarı oranları olmasına rağmen uzun dönemde biyolojik ve protetik komplikasyonlar görülebilmektedir. ${ }^{5}$

\footnotetext{
${ }^{*}$ Mevcut çalışma Uluslararası Türk Prostodonti ve İmplantoloji Derneği (TPID) 23. Bilimsel Kongresi, Dalaman, Muğla, Türkiye, 2017'de sözlü bildiri olarak sunulmustur.

${ }^{\alpha}$ Çukurova Üniversitesi Diş Hekimliği Fakültesi Protetik Diş Tedavisi Anabilim Dalı, Adana

${ }^{\beta}$ Çukurova Üniversitesi Diş Hekimliği Fakültesi Ağız Diş ve Çene Radyolojisi Anabilim Dalı, Adana

${ }^{\gamma}$ Çukurova Üniversitesi Diş Hekimliği Fakültesi Ağız Diş ve Çene Cerrahisi Anabilim Dalı, Adana
} 
İmplant destekli sabit restorasyonların uzun süreli sağkalımı ve başarısı implant çevresindeki marjinal kemik kayıplarından etkilenebilir. Marjinal kemik kaybı; biyolojik genişlik miktarı, implant-dayanak bağlantısı, peri-implantitis oluşumu veya biyomekanik ve protetik faktörler gibi nedenlerden etkilenebilir. .-11 $^{-11}$

Özellikle estetik bölgelerde implant tedavisinin başarısı için peri-implant yumuşak doku görünümü kritiktir. Yumuşak doku konturü, interproksimal papilla ve gingival çıkış profili dentisyonun bütünü ile uyumlu olmalıdır. Peri-implant marjinal kemik miktarı periimplant mukozayı doğrudan etkilemektedir. ${ }^{12}$

İmplant destekli sabit protezlerde marjinal kemik kaybının birçok faktöre bağlı olduğunu gösteren çalışmalar vardır. Bu faktörler; travmatik cerrahi teknik, erken yükleme ve/veya aşırı yükleme, implantın lokasyonu, implantın şekli, implant iç çeperi-dayanak dış çeperi arası mikro açıklık, mikrobiyal kontaminasyon, biyolojik genişlik ve peri-implant yumuşak doku, peri-implant enflamasyon, implant ve protetik komponent mikro hareketi, tekrarlanan vida torku ve implant boyun geometrisidir. ${ }^{13-22}$

İmplant-dayanak bağlantısı, maksimum çiğneme kuvvetlerine ve ayrıca bakteri penetrasyonuna karşı koyması gerektiği için, dental implantların en zayıf noktalarından birini temsil eder. İmplant ve dayanak arasında marjinal boşluk oluşumu, bakterilerin implant-dayanak ara-yüzüne nüfuz etmesi nedeniyle marjinal kemik kaybının artmasına neden olabilir. ${ }^{23,24}$

Her implant sistemi için implant morfolojisi ve implantdayanak ara-yüz geometrisi farklıdır. Implant dayanak ara-yüz geometrisi, eksternal ve internal olmak üzere temelde iki farklı şekildedir. Eksternal bağlantıda genellikle implant platformunun üzerinde standart eksternal altıgen morfoloji bulunur. İnternal bağlantı uç uca birleşim (butt-joint) ve konik internal bağlantı (Morse konikliği) gibi farklı kategorilerde değerlendirilebilir. İmplantın iç kısmına yerleşen çeşitli internal morfolojileri de (altıgen, sekizgen vb.) içerebilir. ${ }^{25}$

Konik bağlantının, implant-dayanak ara-yüzündeki boşlukları ve mikro-sızıntıyı azalttığı böylece bakteriyel kolonizasyonu geciktirip azaltabileceği öne sürüldü. ${ }^{26}$ Ancak bu morfolojiye sahip bazı sistemlerde bile üretim hatalarına bağlı olarak ara-yüzde tamamen sızdırmazlık sağlanamayabilir. ${ }^{25,26}$ İmplant bağlantısının mekanik etkilerine bakıldığında, farklı bağlantıların okluzal yük altında nasıl davrandığı araştırıldı. Yük altında farklı yollardan dağılan kuvvetler, peri-implant kemiğin aşırı yüklenmesine ve çeşitli komplikasyonlara yol açabilir. ${ }^{27-29}$ İmplant dayanak bağlantısı, hem biyolojik hem mekanik komplikasyonlara yol açabileceği için, implant destekli restorasyonun uzun vadeli başarısı için stratejik bir başlık olarak düşünülmelidir. ${ }^{30}$
İmplant başarısının değerlendirilmesi için Misch ${ }^{31}$ ve ark. tarafından belirlenen dental implantlar için sağlık ölçeği kriterleri Tablo 1'de görülmektedir.

Tablo 1.

Dental implantlar için sağlık ölçeği (Oral Implantolojistlerin Uluslararası Kongresi, Pisa, İtalya, Ortak Görüş Konferansı, 2007)

\begin{tabular}{|c|c|}
\hline \multicolumn{2}{|r|}{ İmplant Kalite Ölçeği } \\
\hline Grup & Klinik Durumlar \\
\hline $\begin{array}{l}\text { 1. Başarı } \\
\text { (Optimum } \\
\text { sağlık) }\end{array}$ & $\begin{array}{l}\text { a. Fonksiyonda ağı veya acı yok } \\
\text { b. } 0 \text { hareketilik (Mobilite) } \\
\text { c. İlk cerrahiden beri radyografik kemik kaybı:<2mm } \\
\text { d. Eksuda öyküsü yok }\end{array}$ \\
\hline $\begin{array}{l}\text { 2. Tatmin Edici } \\
\text { Sağkalım }\end{array}$ & $\begin{array}{l}\text { a. Fonksiyonda ağrı yok } \\
\text { b. } 0 \text { hareketlilik } \\
\text { c. } 2-4 \text { mm'lik radyografik kemik kaybı } \\
\text { d. Eksuda öyküsü yok }\end{array}$ \\
\hline $\begin{array}{l}\text { 3. Sağkalımda } \\
\text { Bozukluk }\end{array}$ & $\begin{array}{l}\text { a. Fonksiyon sırasında hassasiyet olabilir } \\
\text { b. Hareketlilik yok } \\
\text { c. Radyografik kemik kaybı }>4 \mathrm{~mm} \text { (implant gövdesinin } \\
1 / 2 \text { 'Sinden daha az) } \\
\text { d. Prob derinliği }>7 \mathrm{~mm} \\
\text { e. Eksuda öyküsü olabilir }\end{array}$ \\
\hline $\begin{array}{l}\text { 4.Başarısız } \\
\text { (Klinik Veya } \\
\text { Kesin } \\
\text { Başarısızık) }\end{array}$ & $\begin{array}{l}\text { Aşağıdakilerin herhangi biri: } \\
\text { a. Fonksiyon sırasında ağı } \\
\text { b. Hareketlilik } \\
\text { c. Radyografik kemik kaybı: implant uzunluğunun } \\
>1 / 2 \text { 'sinden daha fazla } \\
\text { d. Kontrol edilemeyen eksuda } \\
\text { e. Ağızda yerleşik değil }\end{array}$ \\
\hline
\end{tabular}

$\mathrm{Bu}$ retrospektif pilot çalışmanın amacı farklı internal implant-dayanak bağlantı çeşitlerinin (konik ve uç uca birleşim) bir yıllık implant başarısına etkisinin değerlendirilmesidir.

Mevcut çalışmanın sıfır hipotezi; internal konik ve uç uca birleşimli implant-dayanak bağlantılarının kısa dönem implant başarıları arasında istatiksel olarak anlamlı bir fark olmayacağıdır.

\section{GEREÇ VE YÖNTEM}

Çukurova Üniversitesi Diş Hekimliği Fakültesi'nde tedavileri başlayan ve 2016 yılında implant üstü sabit protetik tedavisi tamamlanan, protetik yükleme sonrası en az 1 yılı geçmiş hastalar kontrol randevularında klinik ve radyografik olarak değerlendirildi. Mevcut pilot çalışmada öncelikle 20 hasta çağırılarak değerlendirmeleri yapıldı. 1 hasta kontrol randevularına gelmediği için çalışma dışında bırakıldı. Hastalar 
çalışmanın içeriği hakkında bilgilendirildi ve hastalardan çalışmaya katılmakta gönüllü olduklarına dair onam formları alındı. Ardından hasta takip formları ile çalışma dahilindeki hastalara ait gerekli sistemik bilgiler, ağız içi durumlar kayıt altına alındı, periodontal ve radyolojik ölçümler elde edildi.

Risk göstergeleri olarak yaş, medikal durum, meslek, cinsiyet ve sigara kullanımı göz önünde bulunduruldu.

Hastaların genel ağız içi ve dışı muayenelerinden sonra mandibular posterior bölgede bulunan birer implantları premolar veya molar diş ayrımı yapılmadan çalışmaya dahil edildi. Mandibular posterior bölgede implantı olmayan hastalarda maksiller posterior bölgedeki implantlar değerlendirmeye alındı. Tedavileri tamamlanmış olan 19 hastada uygulanan 11 konik ve 8 uç uca birleşimli implant dayanak bağlantısının implant başarısına etkisi yüklemeden bir yıl sonra değerlendirildi. Öncelikle klinik değerlendirmeleri yapılan implantlarda; sondlamada kanama ${ }^{32}$, peri-implant cep derinliği, plak indeksi ${ }^{33}$,gingival indeks ${ }^{34,35}$ değerleri kaydedildi. Plak indeksi için Tablo 2'de belirlenen skorlar kullanıldı. Dişin her yüzeyi için ayrı skor verildi ve toplam skor değeri ölçüm yapılan diş yüzey sayısına bölünerek dişe ait skor elde edildi. Gingival indeksi için de Tablo 3'de belirlenen skorlar kullanıldı. Dişin her yüzeyi için ayrı skor verildi ve toplam skor değeri ölçüm yapılan diş yüzey sayısına bölünerek dişe ait skor elde edildi.

\section{Tablo 2.}

\section{Plak indeksi değerleri ${ }^{33}$}

\begin{tabular}{|ll|}
\hline Skor & Klinik Durum \\
\hline 0 & Dişetine komşu bölgede plak yok. \\
\hline 1 & Dişeti kenarında film şeklinde plak var. \\
\hline 2 & $\begin{array}{l}\text { Dişeti cebinde ve dişeti kenarında film şeklinde gözle } \\
\text { görülür derecede plak var. }\end{array}$ \\
\hline 3 & Dişeti cebinde ve dişeti kenarında fazla miktarda plak var. \\
\hline
\end{tabular}

Tablo 3.

\section{Gingival indeks değerleri ${ }^{34,35}$}

\begin{tabular}{|ll|}
\hline Skor & Klinik Durum \\
\hline 0 & Sağlıklı dişeti, enflamasyon yok. \\
\hline 1 & $\begin{array}{l}\text { Dişetinde hafif enflamasyon, renk değişikliği ve hafif ödem } \\
\text { var, sondlamada kanama yok. }\end{array}$ \\
\hline 2 & $\begin{array}{l}\text { Dişetinde orta derecede enflamasyon, kırmızılık ve ödem } \\
\text { var, sondlamada kanama var. }\end{array}$ \\
\hline 3 & $\begin{array}{l}\text { Dişetinde ileri derecede enflamasyon, kızarıklık, ödem var, } \\
\text { spontan kanamalar görülür. }\end{array}$ \\
\hline
\end{tabular}

Radyolojik değerlendirmeler belirlenen referans bölgelerden paralel teknikle çekilmiş periapikal radyograflardan peri-implant kemik kaybı miktarları ölçülerek yapıldı. İki implant dayanak bağlantı tipine ait başarı kriterleri Tablo 1'de görülen dental implantlar için sağlık ölçeği kriterlerine göredeğerlendirildi. Pilot çalışma olduğu için power analizi yapılmadı. Ancak bu pilot çalışmadan elde edilecek sayıdal değerler kullanılarak yapıIması planlanan geriye dönük çalışmada power analizi uygulanması planlandı.

Elde edilen klinik ve radyolojik verilerin analizi için SPSS 18 (IBM Corporation, Armonk, NY, USA) programında t-test, tek yönlü ANOVA ve Tukey testleri kullanıldı $(\alpha=0.05)$.

\section{BULGULAR}

Hastaların demografik verilerine bakıldığı zaman farklı sektörlerden çeşitli meslek gruplarına mensup, yaşları 41 ve 71 arasında değişen, 10 kadın ve 9 erkek hastadan oluşan çalışma grubunda medikal duruma bakıldığında 8 kişide herhangi bir sistemik hastalık yoktu. Hastaların 11 'inde diyabet, hipertansiyon ve anemi gibi kontrol altında olan sistemik hastalık vardı. 14 kişi sigara kullanmazken, 2 kişi günde 10 sigaradan az, 3 kişi ise günde 10 taneden fazla sigara içtiğini belirtti.

Sondlamada kanama, cep derinliği, plak indeksi, gingival indeks, kemik kaybı miktarı değerlendirildiğinde, Tablo 4'de görüldüğü üzere, iki implant dayanak bağlantı tipi arasında kısa dönem implant başarısı açısından istatiksel olarak anlamlı bir fark bulunamadı $(P>0.05)$. Sondlamada kanama indeksine göre bağlantı tiplerinin 1 yıllık değerlendirmesinde; konik bağlantıda $(1.36 \pm 0.50)$ uç-uca bağlantıya $(1.38 \pm 0.52)$ göre daha az kanama skoru olduğu görülmüştür. Cep derinliğinin 1 yıllık miktarları değerlendirildiğinde konik bağlantıda $(1.27 \pm 0.65 \mathrm{~mm})$ uçuca bağlantıya $(1.38 \pm 0.74 \mathrm{~mm})$ göre daha az derinlikte cep gözlendi. Aynı süre için plak indeksleri değerlendirildiğinde uç-uca bağlantıya ait skorların $(0.56 \pm 0.55)$ konik bağlantıya $(0.77 \pm 0.73)$ göre daha az olduğu görüldü. Ayrıca 1 yılın sonunda ortalama gingival indeks miktarları değerlendirildiğinde uç-uca bağlantıda $(0.45 \pm 0.48)$ konik bağlantıya $(0.50 \pm 0.42)$ göre daha az olduğu görüldü. 1 yıllık kemik kaybı değerlendirildiğinde ise konik bağlantıda $(0.29 \pm 0.28 \mathrm{~mm})$ uç-uca bağlantıya $(0.43 \pm 0.29 \mathrm{~mm})$ göre daha az kemik kaybı vardı.

Implant sistemleri kendi aralarında Tablo 5'de görüldüğü üzere ayrı ayrı değerlendirildiğinde farklı implant sistemleri arasında kısa dönem implant başarısı açısından istatistiksel olarak anlamlı bir fark görülemedi $(P>0.05)$. 
Tablo 4.

\section{İmplant dayanak bağlantı tipine göre peri-implant parametrelerin değerlendirilmesi $(\alpha=0.05)$}

\begin{tabular}{|c|c|c|c|c|}
\hline Peri-implant Parametreler & $\begin{array}{l}\text { Bağlantı } \\
\text { Tipi }\end{array}$ & $\mathbf{N}$ & $\begin{array}{l}\text { Ort土Std. } \\
\text { Deviasyon }\end{array}$ & $\mathrm{P}$ \\
\hline \multirow{2}{*}{ Sondlamada Kanama } & Konik & 11 & $1.36 \pm 0.50$ & \multirow{2}{*}{0.96} \\
\hline & Butt Joint & 8 & $1.38 \pm 0.52$ & \\
\hline \multirow{2}{*}{ Ortalama Cep Derinliği (mm) } & Konik & 11 & $1.27 \pm 0.65$ & \multirow{2}{*}{0.75} \\
\hline & Butt Joint & 8 & $1.38 \pm 0.74$ & \\
\hline \multirow{2}{*}{ Plak İndeksi } & Konik & 11 & $0.77 \pm 0.73$ & \multirow{2}{*}{0.50} \\
\hline & Butt Joint & 8 & $0.56 \pm 0.55$ & \\
\hline \multirow{2}{*}{ Gingival İndeks } & Konik & 11 & $0.50 \pm 0.42$ & \multirow{2}{*}{0.81} \\
\hline & Butt Joint & 8 & $0.45 \pm 0.48$ & \\
\hline \multirow{2}{*}{ Ortalama Kemik Kaybı (mm) } & Konik & 11 & $0.29 \pm 0.28$ & \multirow{2}{*}{0.31} \\
\hline & Butt Joint & 8 & $0.43 \pm 0.29$ & \\
\hline
\end{tabular}

Tablo 5.

Peri-implant parametrelerin implant sistemine göre değerlendirilmesi

\begin{tabular}{lccc|}
\multicolumn{4}{c}{ Implant Sistemlerinin Kendi Aralarında Değerlendirilmesi } \\
\hline Implant Sistemleri & $\mathbf{N}$ & $\begin{array}{c}\text { Ortalama Cep } \\
\text { Derinliği } \pm \text { SD } \\
(\mathbf{m m})\end{array}$ & $\begin{array}{c}\text { Ortalama Kemik } \\
\text { Kaybı } \\
(\mathbf{m m})\end{array}$ \\
\hline Implantium & 5 & $1.0 \pm 0.0$ & $0.40 \pm 0.31$ \\
\hline Nucleoss & 3 & $2.0 \pm 0.0$ & $0.43 \pm 0.37$ \\
\hline Bego & 3 & $1.0 \pm 1.0$ & $0.40 \pm 0.36$ \\
\hline Astra EV & 6 & $1.6 \pm 0.9$ & $0.23 \pm 0.24$ \\
\hline Biohorizons & 2 & $1.0 \pm 0.0$ & $0.45 \pm 0.21$ \\
\hline Total & 19 & $1.3 \pm 0.7$ & $0.34 \pm 0.28$
\end{tabular}

\section{TARTIȘMA}

Mevcut çalışmanın sonuçları göz önüne alındığında, çalışmanın sıfır hipotezi kabul edildi. İmplant dayanak bağlantı çeşitleri arasında kısa dönem implant başarısı açısından istatistiksel olarak anlamlı bir fark bulunamadı.

İnternal implant dayanak bağlantısı olan implantlar; marjinal kemik kaybına yol açan biyomekanik ve biyolojik komplikasyonların azaltılması, okluzal yükün kemiğe ve implanta aktarımının iyileştirilmesi, implant dayanak arayüzünde bakteri kolonizasyonunu azaltmak için mikro boşlukların minimuma indirilmesi amacıyla geliştirildi. ${ }^{30}$

Yapılan in vitro çalışmalarda konik ve uç uca implantdayanak bağlantıları mekanik açıdan değerlendirildiğinde her iki bağlantı tipinin de başarılı olduğu belirtildi. Ancak konik implant-dayanak bağlantısı tıkama performansı, mikro açıklık, tork miktarı ve dayanak stabilitesinde daha üstün performans gösterdi. ${ }^{25,36}$
In vitro çalışmalar; konik implant-dayanak bağlantısında diğer bağlantı sistemlerine göre daha az bakteriyel kontaminasyon olduğunu gösterdi. ${ }^{25}$ Ayrıca in vitro çalışmalarda; internal konik implant-dayanak bağlantısında, internal hekzagonal ve eksternal hekzagonal bağlantıya göre implant çevresindeki stresin daha az olduğu gösterildi. ${ }^{24,36,37}$

Marjinal kemik kaybı implant tedavileri sonrasında çeşitli etkenlere bağlı olarak gözlenmektedir. Schmitt ve ark. ${ }^{25}$ tarafından yapılan sistematik derlemede implant sağ-kalımı ve başarı oranları değerlendirildiğinde konik ve konik olmayan implant dayanak bağlantı sistemlerinin istatiksel açıdan anlamlı bir farklılık göstermediği görüldü. Ancak yapılan çalışmalarda konik implantdayanak bağlantısında diğer sistemlere göre daha az kemik kaybı görülmektedir. ${ }^{38,39}$ Mevcut çalışmada da konik ve konik olmayan implant dayanak bağlantı sistemlerinin istatiksel olarak anlamlı farklılık göstermediği ancak marjinal kemik kaybının, konik implant dayanak bağlantı tipinde daha az olduğu bulundu.

Atieh ve ark. ${ }^{40}$ tarafından yapılan sistematik derlemede konik ve uç uca implant-dayanak bağlantısı olan implantlar karşılaştırıldığında, mevcut çalışma ile benzer şekilde, implant başarısı açısından istatiksel olarak anlamlı bir fark bulunamadı. Marjinal kemik kaybı değerlendirildiğinde ise konik implant dayanak bağlantısında istatiksel olarak anlamlı fark bulunmuş ve konik bağlantıda daha az kemik kaybı olduğu görüldü.

Caricasulo ve ark. ${ }^{30}$ tarafından yapılan sistematik derlemede farklı implant-dayanak bağlantı tiplerinin (eksternal hegzagonal, internal hegzagonal ve internal konik) başarılı bir implant üstü protez rehabilitasyonu elde edilmesini mümkün kılabileceği sonucuna varıldı. Marjinal kemik kaybının internal implant-dayanak bağlantısı kullanıldığında kısa ve orta süreli takibinde daha düşük olduğu görüldü. Özellikle konik bağlantının; implant-dayanak ara-yüzünde daha iyi tıkama performansı ve stabilite gösterdiği için daha avantajlı olduğu öngörüldü.

Enkling ve ark. ${ }^{41}$ tarafından yapılan çalışmada,12 aylık takip süresi sonunda konik implant-dayanak bağlantısının uç uca implant-dayanak bağlantısı ile karşılaştırıldığı radyografik incelenmesinde dikey ve yatay marjinal kemik kaybının miktarı ölçüldü. İki boyutta da farklılıklar istatiksel olarak anlamlı bulunmadı.

Linde ve ark. ${ }^{42}$ peri-implantitisi; $>4 \mathrm{~mm}$ artmış sulkus derinliği, sondlamada kanama ve/veya süpürasyon ve $\geq 2 \mathrm{~mm}$ marjinal kemik kaybı 
olarak tanımladı. Dalago ve ark..$^{43}$ peri-implantitis ile ilgili yaptığı çalışmada plak indeksini ve gingival indeksi risk indikatörleri olarak belirtti. Canullo ve ark. ${ }^{44}$ tarafından yapılan randomize kontrollü çalışmada çekim bölgelerine yerleştirilen implantlar konik implant-dayanak bağlantısı ve uç uca implant-dayanak bağlantısına sahip kuronlarla restore edildi. 25 aylık takip süresinden sonra marjinal kemik seviyelerinde belirgin farklılık gözlendi, ancak periodontal parametreler iki grup arasında istatiksel olarak anlamlı bir fark göstermedi. Pessoa ve ark. ${ }^{45}$ yaptıkları çalışmada implant dayanak bağlantı tipi ile gingival indeks değerlendirildiğinde anlamlı bir farklıık gözlenmedi. Mevcut çalışmada da benzer şekilde implant dayanak bağlantı tiplerinin kısa süreli takibinde periodontal parametreler açısından istatiksel olarak anlamlı bir fark bulunmadı.

Mevcut pilot çalışmanın retrospektif ve kısa süreli takip olması ve çalışmaya dahil edilen hasta sayısının nispeten az olması limitasyonları göz önünde bulundurulmalıdır. Ancak, mevcut çalışmanın daha büyük örneklem üzerinde gerçekleştirilmesi planlanan bir çalışmanın ön çalışması olduğu unutulmamalıdır. İmplant-dayanak bağlantı tipinin implantın uzun dönem başarısı üzerine etkisini daha büyük örneklem kullanarak değerlendiren randomize kontrollü klinik araştırmalara intiyaç duyulmaktadır. Zira bu tür çalışmaların daha yüksek klinik kanıt değeri taşıdığı bilinmelidir.

Iki bağlantı tipi arasında marjinal kemik kaybı açısından istatistiksel açıdan anlamlı bir fark bulunamadı. Ancak, birinci yılın sonunda internal konik olmayan bağlantı tipinde konik bağlantı grubunun neredeyse 1.5 katı kadar bir kemik kaybı gözlendi. Aradaki fark bu şekilde artarak devam edecek olursa orta ve uzun dönemde marjinal kemik kaybı için klinik açıdan fark olacağı tahmin edilmektedir.

\section{SONUÇ}

1. Bu retrospektif pilot çalışma; implant-dayanak bağlantısının, kısa süreli takipte klinik parametreler üzerinde herhangi önemli bir etkisinin olmadığını gösterdi.

2. Mevcut pilot çalışma implant-dayanak bağlantısının, kısa dönem radyografik kemik açısından istatistiksel açıdan anlamlı bir etkisinin olmadığını gösterdi.

3. Implant-dayanak bağlantı tipinin implantın uzun dönem başarısı üzerine etkisini daha fazla sayıda örneklem üzerinden değerlendiren randomize kontrollü prospektif klinik araştırmalara intiyaç duyulmaktadır. 


\section{KAYNAKLAR}

1. Alonso-Gonzalez R, Aloy-Prosper A, PenarrochaOltra D, Penarrocha-Diago MA, Penarrocha-Diago M. Marginal bone loss in relation to platform switching implant insertion depth: An update. J Clin Exp Dent. 2012; 4(3): 173-9.

2. Kadkhoda Z, Amarlu Z, Eshraghi S, Samiei N. Antimicrobial effect of chlorhexidine on Aggregatibacter actinomycetemcomitans biofilms associated with peri-implantitis. J Dent Res Dent Clin Dent Prospects. 2016; 10(3): 176-80.

3. Canullo L, Fedele GR, lannello G, Jepsen S. Platform switching and marginal bone-level alterations: the results of a randomized-controlled trial. Clin Oral Implants Res. 2010; 21(1): 115-21.

4. Raoofi S, Khademi M, Amid R, Kadkhodazadeh M, Movahhedi MR. Comparison of the Effect of Three Abutment-implant Connections on Stress Distribution at the Internal Surface of Dental Implants: A Finite Element Analysis. J Dent Res Dent Clin Dent Prospects. 2013; 7(3): 132-9.

5. Mangano $C$, laculli F, Piattelli A, Mangano F. Fixed restorations supported by Morse-taper connection implants: a retrospective clinical study with 10-20 years of follow-up. Clin Oral Implants Res. 2015; 26(10): 1229-36.

6. Berglundh T, Lindhe J. Dimension of the periimplant mucosa. Biological width revisited. J Clin Periodontol. 1996; 23(10): 971-3.

7. Hermann JS, Buser D, Schenk RK, Cochran DL. Crestal bone changes around titanium implants. A histometric evaluation of unloaded non-submerged and submerged implants in the canine mandible. $\mathrm{J}$ Periodontol. 2000; 71(9): 1412-4.

8. Broggini N, McManus LM, Hermann JS, Medina R, Schenk RK, Buser D et al. Peri-implant inflammation defined by the implant-abutment interface. J Dent Res. 2006; 85(5): 473-8.

9. Zitzmann NU, Berglundh T. Definition and prevalence of peri-implant diseases. $J$ Clin Periodontol. 2008; 35(8): 286-91.

10.Lang NP, Berglundh T, Working Group 4 of Seventh European Workshop on Periodontology. Periimplant diseases: where are we now? Consensus of the Seventh European Workshop on Periodontology. J Clin Periodontol. 2011; 38(11): 178-81.

11. Fu JH, Hsu YT, Wang HL. Identifying occlusal overload and how to deal with it to avoid marginal bone loss around implants. Eur J Oral Implantol. 2012; 5(1): 91-103.

12. Choquet V, Hermans $M$, Adriaenssens $P$, Daelemans P, Tarnow DP, Malevez C. Clinical and radiographic evaluation of the papilla level adjacent to single-tooth dental implants. A retrospective study in the maxillary anterior region. J Periodontol. 2001; 72(10): 1364-71.
13.Becker W, Goldstein M, Becker BE, Sennerby L. Minimally invasive flapless implant surgery: A prospective multicenter study. Clin Implant Dent Relat Res. 2005; 7(Suppl1): S21-7.

14. Kim Y, Oh TJ, Misch CE, Wang HL. Occlusal considerations in implant therapy: Clinical guidelines with biomechanical rationale. Clin Oral Implants Res. 2005; 16(1): 26-35.

15. Hermann JS, Schoolfield JD, Schenk RK, Buser $D$, Cochran DL. Influence of the size of the microgap on crestal bone changes around titanium implants. A histometric evaluation of unloaded non-submerged implants in the canine mandible. J Periodontol. 2001; 72(10): 1372-83.

16. Weng D, Nagata MJ, Bell M, Bosco AF, de Melo LG, Richter EJ. Influence of microgap location and configuration on the periimplant bone morphology in submerged implants. An experimental study in dogs. Clin Oral Implants Res. 2008; 19(11): 1141-7.

17. Ericsson I, Persson LG, Berglundh T, Marinello $\mathrm{CP}$, Lindhe J, Klinge B. Different types of inflammatory reactions in peri-implant soft tissues. J Clin Periodontol. 1995; 22(3): 255-61.

18. Myshin HL, Wiens JP. Factors affecting soft tissue around dental implants: A review of the literature. J Prosthet Dent. 2005; 94(5): 440-4.

19. King GN, Hermann JS, Schoolfield JD, Buser D, Cochran DL. Influence of the size of the microgap on crestal bone levels in non-submerged dental implants: A radiographic study in the canine mandible. J Periodontol. 2002; 73(10): 1111-7.

20.Abrahamsson I, Berglundh T, Lindhe J. The mucosal barrier following abutment dis/reconnection. An experimental study in dogs. J Clin Periodontol. 1997; 24(8): 568-72.

21. Bratu EA, Tandlich M, Shapira L. A rough surface implant neck with microthreads reduces the amount of marginal bone loss: A prospective clinical study. Clin Oral Implants Res. 2009; 20(8): 827-32.

22. Roos-Jansaker AM, Lindahl C, Renvert $\mathrm{H}$, Renvert S. Nine-to fourteen-year follow-up of implant treatment. Part II: presence of peri-implant lesions. J Clin Periodontol. 2006; 33(4): 290-5.

23.Tesmer $M$, Wallet $S$, Koutouzis $T$, Lundgren $T$. Bacterial colonization of the dental implant fixtureabutment interface: an in vitro study. Journal of Periodontology. 2009; 80(12): 1991-7.

24. Merz BR, Hunenbart S, Belser UC. Mechanics of the implant-abutment connection: an 8-degree taper compared to a butt joint connection. International Journal of Oral \& Maxillofacial Implants. 2000; 15(4): 519-26. 
25.Schmitt CM, Nogueira-Filho G, Tenenbaum HC, Lai JY, Britto C, Döring $\mathrm{H}$, et al. Performance of conical abutment (Morse Taper) connection implants: a systematic review. J Biomed Mater Res A. 2014; 102(2): 552-74.

26.Jansen VK, Conrads G, Richter EJ. Microbial leakage and marginal fit of the implant-abutment interface. Int J Oral Maxillofac Implants. 1997; 12(5): 527-40.

27. Hansson S. Implant-abutment interface: biomechanical study of flat top versus conical. Clin Implant Dent Relat Res. 2000; 2(1): 33-41.

28. Hansson S. A conical implant-abutment interface at the level of the marginal bone improves the distribution of stresses in the supporting bone. An axisymmetric finite element analysis. Clin Oral Implants Res. 2003; 14(3): 286-93.

29. Gracis S, Michalakis K, Vigolo P, Vult von Steyern $P$, Zwahlen M, Sailer I. Internal vs. external connections for abutments/reconstructions: a systematic review. Clin Oral Implants Res. 2012; 23(6): 202-16.

30.Caricasulo R, Malchiodi L, Ghensi P, Fantozzi G, Cucchi A. The influence of implant-abutment connection to peri-implant bone loss: A systematic review and meta-analysis. Clin Implant Dent Relat Res. 2018; 20(4): 653-64.

31. Misch CE, Rerel ML, Wang H, Sammartino G, Galindo-Moreno P, Trisi P, et al. Implant success, survival and failure: the International Congress of Oral Implantologists (ICOI) Pisa Consensus Conference. Implant Dentistry. 2008; 17(1): 5-15.

32. Ainamo J, Bay I. Problems and proposals for recording gingivitis and plaque. International Dental Journal. 1975: 25(4): 229-35.

33. Silness J, Löe H. Periodontal disease in pregnancy II. Correlation between oral hygiene and periodontal condition. Acta odontologica scandinavica. 1964; 22(1): 121-35.

34. Löe H, Silness J. Periodontal disease in pregnancy I. Prevalence and severity. Acta odontologica scandinavica. 1963; 21(6): 533-51.

35. Löe $\mathrm{H}$. The gingival index, the plaque index and the retention index systems. The Journal of Periodontology. 1967; 38(Suppl): 610-6.

36.Pessoa RS, Muraru L, Junior EM, Vaz LG, Sloten JV, Duyck J, Jaecques SV. Influence of implant connection type on the biomechanical environment of immediately placed implants CTbased nonlinear, three-dimensional finite element analysis. Clinical Implant Dentistry and Related Research. 2010; 12(3): 219-34.

37.Alkan I, Sertgoz A, Ekici B. Influence of occlusal forces on stress distribution in preloaded dental implant screws. Journal of Prosthetic Dentistry. 2004; 91(4): 319-25.
38.Crespi R, Cappare P, Gherlone E. Radiographic evaluation of marginal bone levels around platformswitched and non-platform-switched implants used in an immediate loading protocol. International Journal of Oral \& Maxillofacial Implants. 2009;24(5):920-6.

39. Bilhan H, Kutay O, Arat S, Cekici A, Cehreli MC. Astra Tech, Branemark, and ITI implants in the rehabilitation of partial edentulism: two-year results. Implant Dentistry. 2010;19(5):437-46.

40.Atieh M, Ibrahim $H$, Atieh A. Platform Switching for Marginal Bone Preservation Around Dental Implants: a Systematic Review and Meta-Analysis. J Periodontol. 2010;81(10):1350-66.

41. Enkling N, Johren P, Klimberg V, Bayer S, MericskeStern R, Jepsen S. Effect of platform switching on peri-implant bone levels: a randomized clinical trial. Clin. Oral Impl. Res. 2011;22(10):1185-92.

42. Lindhe J, Meyle J.\& Group D of European Work-shop on Periodontology. Peri-implant diseases: Consensus Report of the Sixth European Workshop on Periodontology. Journal of Clinical Periodontology. 2008; 35: 282-5.

43. Dalago HR, Schuldt Filho G, Rodrigues MAP, Renvert S, Bianchini MA. Risk indicators for periimplantitis. A cross-sectional study with 916 implants. Clin. Oral Impl. Res. 2016;28(2):1-7.

44. Canullo L, Goglia G, Iurlaro G, Iannello G. Short-term bone level observations associated with platform switching in immediately placed and restored single maxillary implants: A preliminary report. Int $\mathbf{J}$ Prosthodont. 2009;22(3):277-82.

45.Pessoa RS, Sousa RM, Pereira LM, Neves FD, Bezerra FJB, Jaecques SVN et al. Bone remodeling around implants with external hexagon and morsetaper connections: A randomized, controlled, splitmouth, clinical trial. Clinical Implant Dentistry and Related Research. 2017;19(1):97-110.

Yazışma Adresi:

Fatma USLU

İstanbul Okan Üniversitesi Diş Hekimliği Fakültesi

Protetik Diş Tedavisi AD

34959 Akfırat-Tuzla, İstanbul, Türkiye

Tel : $\quad$ +902166771630

E Posta: dtfatmauslu@gmail.com 